\title{
Zoo Attractions and Trinidadian Student Attitudes toward Animal Welfare
}

\author{
Karima Pragg \\ Department of Behavioural Sciences, Faculty of Social Sciences, The University of the West Indies, Jamaica
}

Copyright $\odot 2019$ by authors, all rights reserved. Authors agree that this article remains permanently open access under the terms of the Creative Commons Attribution License 4.0 International License

\begin{abstract}
The issue of animal welfare has slowly risen to the fore in Trinidad and Tobago. The importation of the Caribbean's first two giraffes, Mandela and Melman, into the Emperor Valley Zoo, Trinidad has piqued the interest of the national community. The present quantitative study sought to explore student attitudes toward animal welfare and Mandela and Melman as zoo attractions in two student populations: first year sociology $(n=90)$ and veterinary medicine students $(n=34)$ and to assess the extent to which area of study and gender impact upon their attitudes. Participants were administered a structured questionnaire comprising two scales: the Animal Attitude Scale (AAS) to measure student attitudes to the various uses of animals in society, and a separate scale developed for this study to measure their attitudes toward Mandela and Melman. Gender accounted for a significant amount of the variance in student welfare attitudes. Female students expressed more positive attitudes toward animal welfare and toward Mandela and Melman. A weak statistical relationship was found between area of study and student welfare concerns. However, it was concluded that students were generally concerned about the welfare of animals and expressed positive attitudes toward welfare issues.
\end{abstract}

Keywords Animal Attitude Scale, Animal Welfare, Giraffe, Humane Education, Student Attitudes, Zoo

\section{Introduction}

The area of human-animal interation (HAI) is an "all encompassing” (Thew et al 2015: 11) field that traditionally explored the complexities of human-animal bonds with a sole focus upon animal companionship and animal-assisted therapy. This conventional focus characterizes HAI in Trinidad and Tobago. On the one hand the keeping of pets has been a common practice among the Trinidad and Tobago population and on the other, animals have been often incorporated into therapy sessions through organizations such as The Healing with Horses Foundation.

However, the scope of HAI has since expanded and currently utilizes various sociological and psychological approaches to broaden the plethora of research to include HAI with both zoo and laboratory animal populations (Hosey \& Melfi 2014)[23]. Such expansion has become necessary due to our paradoxical attitudes toward animals (Herzog 2002)[20] and their uses in society. This paradox stems from our conflicting traits: the natural desire to dominate animals and the simultaneous concern for their welfare (Serpell 1996) [41]. Such paradoxes also characterize HAI in Trinidad and Tobago.

While it must be noted that there are no animal testing labs in Trinidad and Tobago, animals are dominated through seasonal hunting and other forms of human amusement in the confined displays of the capital city's Emperor Valley Zoo. Since its establishment in 1952, this zoo has claimed to be working in tandem with the public to promote animal welfare, protect wildlife habitats and prevent cruelty towards animals, though educating the visiting public about these issues is not listed on its website.

\subsection{Animal Welfare}

Animal welfare broadly refers to the physical and emotional wellbeing of wild, captive, farm and domestic nonhuman animals. It takes into account their treatment, health, happiness and safety. According to the World Organization for Animal Health (OIE),

"An animal is in a good state of welfare if it is healthy, comfortable, well-nourished, safe, able to express innate behaviour, and if it is not suffering from unpleasant states such as pain, fear or distress," (Bousfield \& Brown 2010: 2)[6].

Consequently, welfare concerns are not solely centered on addressing animal cruelty, but also upon promoting positive welfare attitudes toward animals' mental and physical health and freedom to fulfill natural needs and 
desires (Bousfield \& Brown 2010) [6].

Large-scale international bodies such as the International Fund for Animal Welfare (IFAW) and smaller local non-governmental organizations including the Royal Society for the Prevention of Cruelty to Animals (RSPCA) in the UK, and the Trinidad and Tobago Society for the Prevention of Cruelty to Animals (TTSPCA) and Animal Welfare Network (AWN) in Trinidad and Tobago promote such concerns and work toward improving the welfare of animals. The TTSPCA and AWN work hand-in-hand to raise awareness of the plight of animals and to educate the public about proper care for and safe interaction with nonhuman animals.

\subsection{Aims of the Study}

In light of the above, the current paper will examine the attitudes of first year sociology and veterinary science students toward animal welfare. This choice of discipline was informed by earlier studies conducted on foreign student populations. For example, previous researchers have focused upon entry-level undergraduates (see Davey 2006)[8] and have found high empathy levels among first year veterinary students in particular (Paul \& Podberseck 2000) [36]. Also, Irvine (2008)[24] explained that since sociology concerns itself with the study of society and human interaction, sociological research should inherently examine HAI since animals are an integral part of our social environments. Therefore, given the nature of this discipline, it was anticipated that sociology students would make an interesting comparative group for the present investigation and it was for this reason that they were included in the study.

This paper will also assess student attitudes toward Mandela and Melman as attractions in the Emperor Valley Zoo and ascertain the extent to which Nibert's assumptions can be applied to Trinidadian society. The impact of gender and area of study upon such attitudes will also be outlined. It was anticipated that previously established gender effects in attitude toward animal welfare would be replicated in the current sample and that pro-welfare scores will be higher for veterinary students than for sociology students.

\section{Review of Related Literature}

There is much debate surrounding the place of animals in human society and the morals that guide HAIs. Among other things, animals provide humans with food, clothes, security, and companionship and writers such as Broom (n.d)[7] believe that humans are obligated to ensure the welfare of nonhuman animals given such interactions with them. However, animal welfare concerns are not always top priority, especially from a cost-benefit standpoint (Lusk \& Norwood 2012)[27] and researchers argue that speciesism may be one reason for this inadequacy (Bekoff \& Gruen 1993)[4]. This form of institutionalized prejudice against animals is premised upon the assumption of human supremacy and legitimizes the exploitation of animals mainly because of species membership (Bekoff \& Gruen 1993)[4]. This ideology has a direct impact upon the treatment of animals and by extension, animal welfare and attitudes toward welfare.

\subsection{Student Attitudes toward the Welfare of Captive Animals}

Rhoads and Goldsworthy (1979) [39] have found that college students perceived zoo animals as confined, unhappy and more dependent than animals that live in their natural environment. However, it must be noted that this study is dated and since then, organizations such as the World Association of Zoos and Aquariums (WAZA) have been increasingly emphasizing the need to enrich the lives of captive animals. Their findings however, may still be valid in territories where zoos are of a similar standard to those in the 1979 study. Trinidad's Emperor Valley Zoo may mirror such standards since much of the animals on display are still housed behind chain-linked fences and contained in concrete pits.

More recent studies have identified gender as a significant variable affecting student attitudes toward animal welfare in general. Researchers demonstrated that female students were more empathetic than male students and therefore expressed greater concern for animal welfare issues (see Mathews \& Herzog (1997)[30], Paul \& Podberseck (2000) [36], Phillips \& McCullough (2005) [37], Signal \& Taylor (2006) on this topic). Herzog et al (1991)[22] suggested that females are more humanistic and are therefore less tolerant of animal abuse while males are more tolerant of hunting and animal testing given their deterministic nature.

This gender construct also applies to the attitudes of students pursuing veterinary medicine. Serpell (2004) [42] reported that female veterinary students are more concerned about animal suffering than their male colleagues and expressed greatest opposition to practices such as hunting, cockfighting and using live animals for surgical procedures.

Similarly, Hazel et al (2011) [19] recorded that female veterinary students scored higher on animal attitude scales than their male classmates. This increased empathy among female veterinary students may be attributed to the feminization of the profession (de Boo \& Knight 2005) [9] and to the incorporation of animal welfare courses into the veterinary school syllabus (Hazel et al. 2011) [19].

Other variables impacting upon student attitudes toward animal welfare include personality (Mathews \& Herzog 1997) [30], culture (Morris 1998) [33] and nationality (Phillips \& McCullough 2005)[37].

Much of the existing literature on animal welfare 
previously discussed speaks to an international audience and examines HAI in territories external to the Caribbean region. There is limited Caribbean literature on animal welfare and this necessitates immediate research within this area. Even though few studies have been conduced by Fielding and Ostberg (2008) [16], Fielding (2008)[15] and Fielding (n.d)[14] in Caribbean territories, these investigations focused solely upon domestic animals, particularly dogs, and not upon exotic animals in captivity. Therefore the present study will address this discrepancy by documenting student attitudes toward the welfare of zoo animals and even serve as a springboard from which future interrogation of Caribbean peoples' concern for the welfare of animals can be triggered.

\subsection{The Role of Zoos in Animal Welfare and Species Conservation}

Historically, zoos primarily functioned as centres for entertainment and animal exhibitions. Despite the fact that modern zoos now incorporate conservation, welfare and education programs into their schemas (Fernandez et al 2009) [13], their role in ensuring the welfare of captive animals and survival of endangered species continues to be a debatable topic. Some writers even question the impact of zoo's ex-situ conservation efforts and outline the stress, boredom and aggravation endured by captive animals (Dell' Amore 2014[11]; Smith-Spark \& Brumfield 2014 [45]; Vaughan 2014) [48].

While the literature acknowledges attempts made by modern zoos to reinvent and market themselves as education, conservation and research facilities ( $\mathrm{Fa}$ et al 2014[12]; Kallipoliti 2011; Mazur \& Clark 2001) [31], some writers maintain that the contributions of these efforts toward animal welfare, human education (Moriarty 1998[32]; Fravel 2003)[17] and improving visitor welfare attitudes (Marino et al 2010)[28] are yet to be proven. Such programs are still in their infancy at Trinidad's Emperor Valley Zoo, which is currently upgrading its existing facilities to accommodate its new giraffe and wildcat residents and research is yet to confirm if its visitors are more educated about animal welfare post-visit.

Though the faces of zoos appear to be changing, some researchers suggest that their foundations still perpetuate speciesism, remain tangible markers of human dominance over nature (Moriarty 1998) [32] and focus primarily upon exploiting, exhibiting (Shea 2014) [43], trading, managing and breeding wild animals for human entertainment (Tyson 2014) [47].

\subsection{Speciesism and HAI}

Some writers draw parallels between human oppression of nonhuman animals and oppression of some racial and ethnic groups in human society (Irvine 2008)[24]. Scholars such as Nibert believe that forms of oppression are rooted in society's structure and belief systems and therefore form part of cultural practices within human societies (Nibert 2003) [34]. Consequently speciesism may be understood as an institutionalized form of discrimination (Steinbock, 1978) [46].

Nibert theorizes that the forces producing ethnic stratification can be easily applied to explaining speciesism. He examines Noel's (1968) theoretical framework explaining ethnic stratification and draws parallels between animal exploitation and other forms of oppression within human society. It is from this position that Nibert draws connections between human oppression and the oppression of nonhuman animals.

For instance, humans use animals for food, clothing, sport and scientific experiments (Irvine 2008)[24] and each of these practices contributes toward human economic gain. Second, cages, chains and weaponry allow humans to wield power over animals. Finally, this unequal power distribution is legitimized by the ideological underpinnings of human society and the overall belief in innate human supremacy (Nibert 2003). Consequently, it can be argued that speciesism is learned as attitudes toward animals are deeply embedded in the social structure.

Hence, Nibert draws a link between exploitation and human use of animals in society. Accordingly his enquiry allows for a theoretical understanding of the functions of nonhuman animals in society and the subsequent impacts upon animal welfare. These analyses put forward by Nibert were used to frame the current study on student attitudes toward animal welfare.

\section{Research Methodology}

\subsection{Participants}

Participants in this study comprised undergraduate students $(n=124)$ enrolled in introductory sociology and veterinary classes at the St. Augustine and Mt. Hope campuses of the University of the West Indies (UWI), Trinidad. The St. Augustine campus is the larger of both campuses in terms of student enrolment and the number of programmes offered. Here students are able to pursue courses through the faculties of Engineering, Food and Agriculture, Humanities and Education, Law, Science and Technology, and Social Sciences. The faculty of Medical Sciences is the only UWI faculty located at the Mt. Hope Medical Sciences Complex where they are often offered student internships. Students at this campus pursue courses in Human Medicine, Veterinary Medicine, Dentistry and Pharmacy.

The sample consisted of 46 males and 78 females. Participants were selected via convenience sampling since the population for the present study could have been easily accessed at the university. In order to encounter potential participants, it was decided that questionnaire distribution would target two compulsory lectures for first year sociology and veterinary science students respectively. 
These lectures included the introduction to sociology course at St. Augustine and the veterinary clinical skills course at Mt. Hope. At the end of these sessions, the study was introduced, its rationale and significance were explained to the students and questionnaires were subsequently distributed to those who were willing to participate in the study. All questionnaires were completed on site and were returned to the administrator as participants exited the lecture halls.

Demographic data on variables such as race and age were not collected because the impact of such variables upon student attitudes was not under investigation. However, given that students in these introductory classes were recent graduated from Secondary school, it can be assumed that their ages ranged between 19 and 22 years.

\subsection{Measurement Instrument}

This study aimed to measure student opinions on animal welfare and consequently employed a quantitative research methodology. A structured questionnaire was designed to measure student attitudes toward animal welfare and toward Mandela and Melman as zoo attractions. The questionnaire consisted of 34 close-ended questions- two questions eliciting demographic data including gender and faculty-and the remaining 32 questions measuring student attitudes toward animal welfare and Mandela and Melman.

The Animal Attitude Scale (AAS) (Herzog et al. 1991)[22] was used to measure student attitudes toward animal welfare concerns. This scale consists of 20 items that are answered on a 5-point Likert scale and are outlined in Table 1. These Likert-type items measure respondents' ethical views on society's uses of animals for scientific research, food, clothing, entertainment and hunting. However, these statements did not assess the tendency of persons to actually engage in action to assist animals. Items on the scale were scored so that a high score would indicate pro-animal welfare attitudes $(H$. Herzog, personal communication, February 4, 2014). Previous use of the AAS has exhibited high internal consistency (Cronbach's $\alpha$ $=$.91; Mathews \& Herzog, 1997[30]; Cronbach's $\alpha=$.86; Signal \& Taylor 2006b)[44]. It was pretested among 35 students and an alpha of $\alpha=.73$ was obtained.

A second set of 12 close-ended statements was developed specifically for the present study and used to measure student attitudes toward Mandela and Melman. These likert-type items were pretested among the same 35 students and a high score of internal consistency was revealed (Cronbach's $\alpha=.86$ ). These items measured respondents' concern for Mandela and Melman as zoo attractions, their satisfaction with the giraffe enclosures at the Emperor Valley Zoo and their willingness to help return Mandela and Melman to the wild. Total scale scores range from 12 to 60 with a high scale score indicative of pro-attitudes toward Mandela and Melman and general concern for their welfare.

This questionnaire was distributed to the 134 study participants, all of whom completed the survey and an alpha of $\alpha=.72$ was obtained.

\subsection{Research Questions}

Student opinions on the various uses of nonhuman animals within society were explored and the following research questions were drafted based on Nibert's theoretical assumptions:

1. What are student opinions on using animals for food, fur coats and zoo attractions?

2. How supportive are students of animal testing?

3. How strongly do students agree that humans have the right to dominate animals?

\subsection{Data Analysis}

Data were analyzed using SPSS v.20.0 and parametric tests including the t-test and Pearson's correlation were used to examine the impact, if any, of gender and area of study upon student attitudes toward animal welfare.

\section{Results of Study}

Raw data from first year sociology $(\mathrm{n}=90)$ and veterinary medicine students $(n=34)$ were entered into SPSS v20.0. There were no instances of missing data.

One of the aims of this study was to investigate whether female students $(n=78)$ had more positive animal welfare attitudes than male students $(n=46)$. An independent samples t-test was conducted to determine if gender had any effect on student responses to items on the AAS. The test reported that females scored higher than males on the AAS $(m=72.81$ and $m=61.20$, respectively). A significant difference between means ( $\mathrm{p}=.000)$ was recorded thereby indicating that gender affected student welfare attitudes.

The correlation between gender and student attitudes toward animal welfare was found to be statistically significant $\left(r=0.35, p=\leq 0.001\right.$, with $r^{2}=0.252$, two-tailed). As depicted in table 1 below, female students' mean scores were higher on each of the scaled items on the Animal Attitude Scale than male scores therefore indicating that female students had higher pro-welfare attitudes. Consequently, gender may be viewed as a predictor of student attitudes toward animal welfare.

Even though female students had more positive attitudes than male students, overall student responses reflected pro-welfare attitudes. This is illustrated in figure 1 below which shows a small standard deviation $($ std $(\mathrm{X})=11.221)$ relative to the mean score $(x=68.5)$ in the distribution of scores on the AAS. This result therefore suggests that student responses generally indicated pro-welfare attitudes since scores close to the mean were frequent. Though the results may not be significant, the data indicates that student attitudes are moving in the right direction since the high mean score suggests that students are indeed concerned about the welfare of animals. 
Table 1. Student means responses to animal welfare concerns according to gender

\begin{tabular}{|c|c|c|c|}
\hline \multicolumn{2}{|r|}{ Animal welfare concerns } & \multicolumn{2}{|c|}{ Mean } \\
\hline & & Male & Female \\
\hline 1. & It is morally wrong to hunt wild animals just for sport. & 4.05 & 4.53 \\
\hline 2. & I do not think that there is anything wrong with using animals in medical research. * & 2.31 & 3.17 \\
\hline 3. & $\begin{array}{l}\text { There should be extremely stiff penalties including jail sentences for people who } \\
\text { participate in cock fighting. }\end{array}$ & 3.51 & 4.00 \\
\hline 4. & $\begin{array}{l}\text { Wild animals, such a mink and raccoon, should not be trapped and their skins made } \\
\text { into fur coats. }\end{array}$ & 3.59 & 4.55 \\
\hline 5. & There is nothing morally wrong with hunting wild animals for food. * & 2.28 & 3.05 \\
\hline 6. & I think people who object to raising animals for meat are too sentimental. * & 2.74 & 3.06 \\
\hline 7. & Much of the scientific research done with animals is unnecessary and cruel. & 2.66 & 3.07 \\
\hline 8. & $\begin{array}{l}\text { I think it is perfectly acceptable for cattle and hogs to be raised for human } \\
\text { consumption.* }\end{array}$ & 2.36 & 2.87 \\
\hline 9. & Basically, humans have the right to use animals as we see fit. * & 3.46 & 4.25 \\
\hline 10. & $\begin{array}{l}\text { The slaughter of whales and dolphins should be immediately stopped even if it } \\
\text { means some people will be out of work. }\end{array}$ & 3.54 & 4.28 \\
\hline 11. & I sometimes get upset when I see wild animals in cages at zoos. & 3.09 & 3.74 \\
\hline 12. & $\begin{array}{l}\text { In general, I think that human economic gain is more important than setting aside } \\
\text { more land for wildlife. * }\end{array}$ & 3.60 & 4.03 \\
\hline 13. & $\begin{array}{l}\text { Too much fuss is made over the welfare of animals these days when there are many } \\
\text { human problems that need to be solved. * }\end{array}$ & 3.42 & 3.98 \\
\hline 14. & Breeding animals for their skins is a legitimate use of animals. * & 3.46 & 4.11 \\
\hline 15. & $\begin{array}{l}\text { Some aspects of Biology can only be learned through dissecting preserved animals } \\
\text { such as cats.* }\end{array}$ & 2.29 & 2.70 \\
\hline 16. & $\begin{array}{l}\text { Continued research with animals will be necessary if we are to ever conquer } \\
\text { diseases such as cancer, heart disease and AIDS. * }\end{array}$ & 1.90 & 2.80 \\
\hline 17. & $\begin{array}{l}\text { It is unethical to breed purebred dogs for pets when millions of dogs are killed in } \\
\text { animal shelters each year. }\end{array}$ & 3.24 & 3.72 \\
\hline 18. & $\begin{array}{l}\text { The production of inexpensive meat, eggs, and dairy products justifies maintaining } \\
\text { animals under crowded conditions. * }\end{array}$ & 2.88 & 3.55 \\
\hline 19. & $\begin{array}{l}\text { The use of animals for testing the safety of cosmetics and household products is } \\
\text { unnecessary and should be stopped. }\end{array}$ & 3.19 & 4.03 \\
\hline 20. & The use of animals in rodeos and circuses is cruel. ${ }^{1}$ & 3.25 & 3.59 \\
\hline & Mean response & 2.87 & 3.65 \\
\hline
\end{tabular}




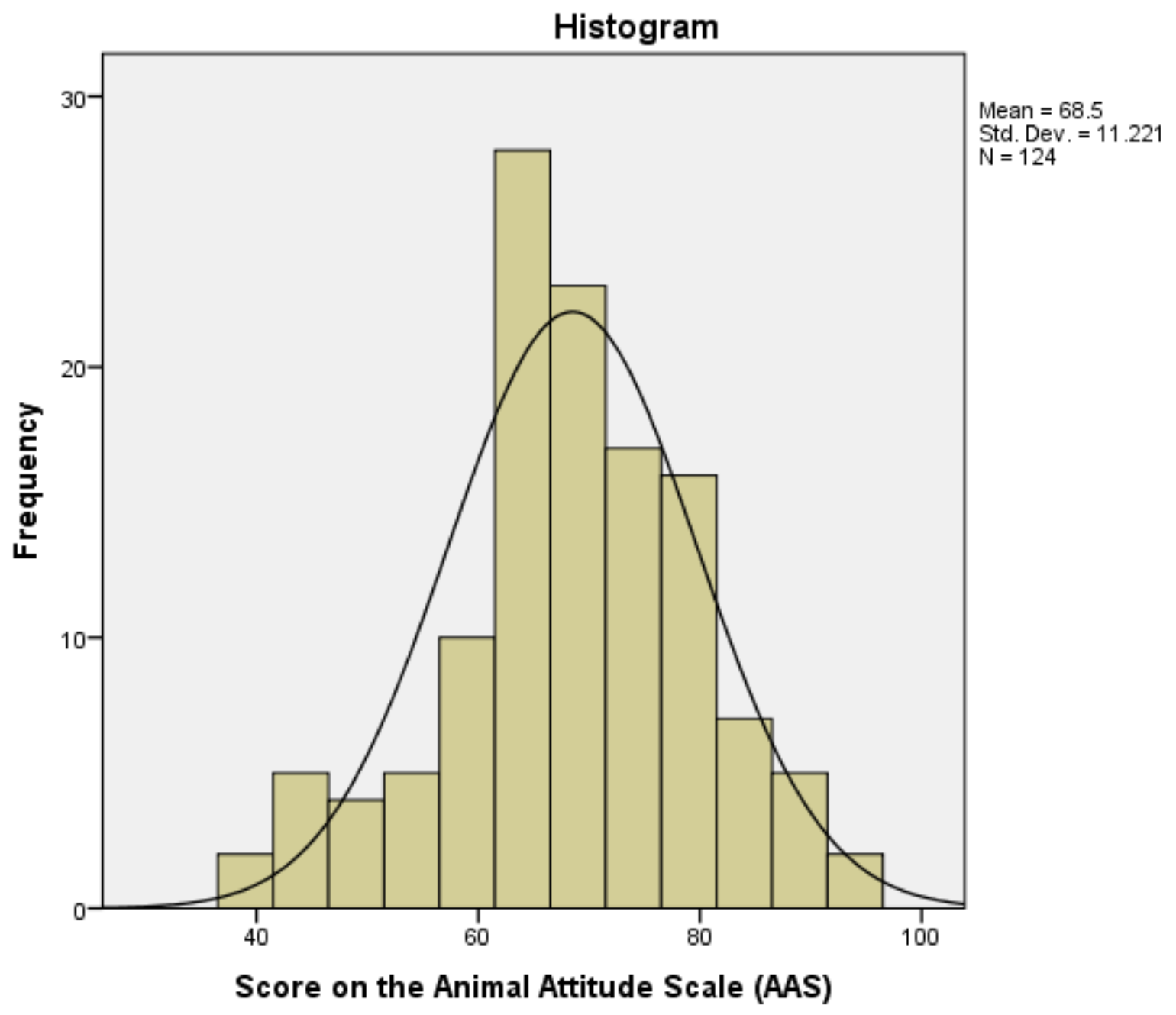

Figure 1. Histogram illustrating frequency distribution of scores on the $\mathrm{AAS}^{2}$ 
Nonetheless, it is important to note is that even though females had higher independent mean scores, both genders were least concerned about animal experimentation and testing. However, the previously discussed paradox surrounding HAI became evident as students appeared to be supportive of the use of animals in scientific research even though they expressed disagreement with the idea that humans have the right to use animals as they deem fit. Yet, both male and female students expressed the most concern about the same three practices involving nonhuman animals in society. They all expressed opposition to

1. Trapping wild animals and turning their skins into coats,

2. Hunting wild animals simply for sporting purposes, and

3. Slaughtering whales and dolphins.

Although gender accounted for $25 \%$ of the variability in student attitude toward animal welfare, it must be noted that gender does not necessarily cause variation in student welfare attitudes.

This study also sought to determine if male and female students had different attitudes toward Mandela and Melman. An independent samples t-test was conducted to examine any effect of gender on student responses to items measuring attitudes toward Mandela and Melman. The test reported that female students scored higher than male students ( $x=44.76$ and $x=41.48$, respectively, $\mathrm{p}=<0.05$ ) and therefore had more positive attitudes toward the giraffes. Further to this, regression analysis (illustrated in table 2 that follows) indicates that gender accounted for $89.3 \%$ of the variability in student attitudes toward animal welfare, $\left(\mathrm{r}^{2}=.893\right)$.

This may imply that students have concern for animal welfare and are generally opposed to Mandela and Melman being housed in the Emperor Valley Zoo. This is illustrated in table 3 below. A significant difference between overall means ( $p=0.009$ ) was reported hence gender also seemed to have an impact upon student attitudes toward Mandela and Melman.

Table 2. Regression analysis of the impacts of area of study and gender upon student attitudes

\begin{tabular}{|c|c|c|c|c|c|c|c|c|c|}
\hline & \multirow[b]{2}{*}{$\mathrm{R}$} & \multirow[b]{2}{*}{ R Square } & \multirow{2}{*}{$\begin{array}{l}\text { Adjusted R } \\
\text { Square }\end{array}$} & \multirow{2}{*}{$\begin{array}{l}\text { Std. Error of the } \\
\text { Estimate }\end{array}$} & \multicolumn{5}{|c|}{ Change Statistics } \\
\hline & & & & & $\begin{array}{l}\text { R Square } \\
\text { Change }\end{array}$ & F Change & df1 & df2 & Sig. F Change \\
\hline 1 & $.175^{\mathrm{a}}$ & .031 & .029 & 10.66010 & .031 & 18.922 & 1 & 596 & .000 \\
\hline 2 & $.961^{\mathrm{b}}$ & .924 & .923 & 2.99537 & .893 & 1739.154 & 4 & 592 & .000 \\
\hline
\end{tabular}

a. Predictors: (Constant), Area of study

b. Predictors: (Constant), Gender ${ }^{3}$

Table 3. Student mean responses to questions on Mandela and Melman according to gender

\begin{tabular}{|c|c|c|c|}
\hline \multirow{2}{*}{\multicolumn{2}{|c|}{ Animal welfare concerns }} & \multicolumn{2}{|c|}{ Mean } \\
\hline & & Male & Female \\
\hline 1. & I am happy that two giraffes have been added as attractions to the Emperor Valley Zoo. * & 1.94 & 2.29 \\
\hline 2. & It makes me sad to know that the giraffe population in the wild is decreasing. & 4.15 & 4.42 \\
\hline 3. & $\begin{array}{l}\text { I do not think that anything is wrong with keeping these two giraffes locked up at the zoo even though their } \\
\text { numbers are depleting.* }\end{array}$ & 2.56 & 3.20 \\
\hline 4. & I care about the preservation of the giraffe species. & 4.31 & 4.32 \\
\hline 5. & I do not sympathize with the giraffes at the Emperor Valley Zoo.* & 3.58 & 4.25 \\
\hline 6. & I would like more giraffes to be introduced to the Emperor Valley Zoo.* & 2.05 & 2.39 \\
\hline 7. & I do not think that these giraffes should be reintroduced into their natural habitat. & 3.34 & 3.54 \\
\hline 8. & I believe that the facilities of the Emperor Valley Zoo can adequately replace the natural habitat of these giraffes.* & 3.25 & 3.54 \\
\hline 9. & Transporting these giraffes in an eight-foot by six-foot wooden crate is animal cruelty. & 3.48 & 3.88 \\
\hline 10. & I want to help return these giraffes to the wild. & 3.60 & 3.36 \\
\hline 11. & I do not care about the welfare of these giraffes.* & 4.29 & 4.48 \\
\hline 12. & I want to learn more about endangered species of giraffe ${ }^{4}$ & 4.13 & 4.22 \\
\hline & Mean response & 3.09 & 3.66 \\
\hline
\end{tabular}


Overall, the results of this study suggested that participants generally had pro-welfare attitudes toward animals and Mandela and Melman. However, more positive attitudes were recorded for female students. Respondents appeared slightly opposed to the use of cages in zoos $(x=3.42)$ and were also of the opinion that the facilities of the Emperor Valley Zoo could not adequately replace the natural habitat of giraffes $(x=3.40)$. Conservation of the remaining species of giraffe was the top concern for both male and female respondents. Respondents objected to displaying animals in zoos for human entertainment (item \#11 on the AAS) and agreed that using animals in rodeos and circuses is cruel (item \#20 on the AAS).

An independent samples t-test was conducted to examine any relationship between area of study and student attitudes to animal welfare and toward Mandela and Melman. It was anticipated that veterinary students $(n=34)$ would have more positive attitudes toward animal welfare than sociology students $(n=90)$. However, in both cases the results of independent samples t-tests found no significance between area of study and attitudes toward both animal welfare and Mandela and Melman ( $>0.1$ ). Furthermore, regression analysis a revealed a weak statistical relationship between area of study and student attitudes $\left(\mathrm{r}^{2}=.031\right)$.

Pearson's correlation was also run to further examine any relationship shared between area of study and student attitudes toward animal welfare and toward Mandela and Melman. As depicted in table 4 below, the relationship between area of study (represented by the label faculty) and student attitudes toward animal welfare appeared to be perfectly negative ( $r=-0.018$, with $r^{2}=0.00$, two-tailed).

Table 4. Correlation between area of study and student attitudes toward animal welfare

\begin{tabular}{|c|c|c|c|}
\hline \multicolumn{3}{|c|}{ Correlations } \\
\hline \multirow{2}{|c|}{} & Faculty & $\begin{array}{c}\text { Score on the } \\
\text { Animal Attitude } \\
\text { Scale (AAS) }\end{array}$ \\
\hline \multirow{2}{*}{ Faculty } & Pearson Correlation & 1 & -.018 \\
\cline { 2 - 4 } & Sig. (2-tailed) & & .844 \\
\cline { 2 - 4 } & $\mathrm{N}$ & 124 & 124 \\
\hline \multirow{2}{*}{$\begin{array}{c}\text { Score on the } \\
\text { Animal Attitude } \\
\text { Scale (AAS) }\end{array}$} & Pearson Correlation & -.018 & 1 \\
\cline { 2 - 4 } & Sig. (2-tailed) & .844 & \\
\cline { 2 - 4 } & $\mathrm{N}$ & 124 & 124 \\
\hline
\end{tabular}

Similarly, as illustrated in the following table 5, area of study and student attitude toward Mandela and Melman also shared a negative relationship $\left(r=-0.129\right.$, with $r^{2}=$ 0.02 , two-tailed).
Table 5. Correlation between area of study and student attitudes toward Mandela and Melman

\begin{tabular}{|c|c|c|c|}
\hline \multicolumn{4}{|c|}{${ }^{6}$ Correlations } \\
\hline & & Faculty & $\begin{array}{l}\text { Score on the } \\
\text { Giraffe Scale }\end{array}$ \\
\hline \multirow{3}{*}{ Faculty } & $\begin{array}{c}\text { Pearson } \\
\text { Correlation }\end{array}$ & 1 & -.129 \\
\hline & Sig. (2-tailed) & & .153 \\
\hline & $\mathrm{N}$ & 124 & 124 \\
\hline \multirow{3}{*}{$\begin{array}{c}\text { Score on the EVZ } \\
\text { Giraffe Scale }\end{array}$} & $\begin{array}{c}\text { Pearson } \\
\text { Correlation } \\
\end{array}$ & -.129 & 1 \\
\hline & Sig. (2-tailed) & .153 & \\
\hline & $\mathrm{N}$ & 124 & 124 \\
\hline
\end{tabular}

\section{Discussion of Results}

\subsection{Limitations}

Prior to discussing the research findings and implications, it is important to acknowledge the methodological limitations of the present investigation of one aspect of human-animal interaction (HAI). This study examined the welfare attitudes of first year sociology and veterinary medicine students at the St. Augustine and Mt. Hope campuses of the UWI. Consequently, given that members of the study population were within the same age cohort, any potential relationship between age and student welfare attitudes could not be investigated.

Additionally, the small number of males made this research more problematic since the sample's female-to-male ratio of 2:1 may have led to the overrepresentation of female opinions. Also, since the number of enrolled sociology students vastly outnumbered that of veterinary medicine students, ideal circumstances for comparison may have been undermined. This may provide one reason why area of study and student attitudes toward animal welfare did not share a strong statistical relationship.

Though, it may also be speculated that student group differences toward animal welfare were not established between veterinary and sociology students because both groups of students may be sensitive to social issues given their areas of study. For instance Hazel, Signal and Taylor (2011)[19] have noted that veterinary students have expressed a natural concern for animals even prior to commencing their course of study. Additionally, the discipline of sociology interrogates various social problems, sensitizes students to these issues and trains them to think clearly and critically (Baker 1981[2] \& Rickles et al 2013) [40]. 


\subsection{Discussion of Findings}

One of the main aims of this research was to assess student attitudes toward animal welfare as measured by the AAS. This research uncovered that students generally had pro-welfare attitudes and a statistically significant correlation between gender and student attitudes toward animal welfare was found. However, further analysis revealed that female students had more positive attitudes toward animal welfare and toward Mandela and Melman than male students and that gender accounted for almost $90 \%$ of the variability in student attitudes toward animal welfare.

Nevertheless, this finding must be interpreted with a degree of caution given that females were overrepresented in the sample since female student enrolment in the sociology and veterinary medicine programs is higher than male enrolment. Such difference in enrolment may be attributed to the fact that the St. Augustine campus is the larger of the two campuses.

Despite this discrepancy in the sample, earlier studies have identified a similar gender gap in attitudes toward animal welfare (Mathews \& Herzog 1997[30]; Phillips \& McCullough 2005[37]; Taylor \& Signal 2005) and animal experimentation (Pifer 1996) [38].

While both genders were found to be tolerant of testing drugs and cosmetic products on animals, female respondents were less tolerant and more empathetic than their male counterparts. Drawing reference from Baron-Cohen's (2003; in de Boo \& Knight 2005)[9] position that hormonal and genetic differences influence behaviour makes it possible to provide one explanation as to why such difference in attitude toward animal testing exists between both genders though, further investigation is needed in order to validate this assumption.

Additionally, culture may have also played an important role in the difference of empathy levels (Baron-Cohen 2011)[3] among male and female study participants. It has been suggested that the homophobic attitudes of Caribbean men often intensify the hypermasculinity felt by them (Youseff 2010) [49] as they strive to perform gender according to the conventional socially acceptable male stereotype. Thus it can be assumed that males were less tolerant toward animal testing since they are traditionally seen as less empathetic (Berk 2006)[5] and may have been performing traditional gender roles.

Further, female students' more positive attitudes toward animal welfare and male students' subsequent less positive attitudes fit into the stereotypical definitions of gender schemas (Bem 1981b; in Lippa 2008)[26] and masculine and feminine behaviour. This dichotomy in gender tolerance for animal testing may also be understood as the product of the self-socialization of gender (Lippa 2002)[26] and individual conformity to socially approved gender roles within the Trinidadian environment.

It is ironic though, that male respondents were mostly opposed to sport hunting, a finding that directly contradicts
Herzog's (2007)[21] research that established strong male support for hunting activities. Consequently, the influence of biology and social learning processes as explanations for apparent differences in student attitudes toward animal welfare extends only to a particular extent. This particular finding of the present investigation is evidence that behaviour cannot be exclusively labelled according to biological characteristics, policing of behaviour or gender stereotypes. It may be suggested that opposition to sport hunting may be due to the fact that this activity is not a common pastime for Trinidadians since hunting practices are illegal for a large portion of the calendar year.

Male and female students were more tolerant of animal experimentation but less tolerant of sport hunting. Such opposition to sport hunting does not necessarily lend support to Nibert's postulation that the ideology of human supremacy leads to oppression and negatively impacts upon animal welfare hence his assumption may not accurately explain beliefs about hunting among Trinidadians. The differences in student attitudes toward animal uses in society according to gender may be indicative that gender acts as a moderating variable between student attitudes and animal welfare.

However, it may be inferred that students were more tolerant of animal testing because such practices lead to medical breakthroughs from which humans benefit while sport hunting involves the killing of animals for human recreation. In this regard, this finding lends support to Nibert's theory. This is because student tolerance for using animals for medical research purposes may be interpreted as support for nonhuman animal exploitation if human gains are to be reaped. This finding may lend support to Serpell's (1996) [41] acknowledgement of the paradoxes that characterize HAI.

\subsection{Recommendations}

The findings of this study and the proposed explanations for its results further develop the nature versus nurture debate vis-à-vis the performance of gender and the stock of research on its impact upon attitudes toward animal welfare. Even though participants of this research were tertiary-aged students and the findings may therefore be restricted to understanding this particular population, conclusions from this study can serve as a platform for future studies that examine any existing relationship between age and student attitudes toward animal welfare. However, it is recommended that a mixed methods approach is undertaken to provide further insight into the attitudes of students in order to more fully understand the context of this phenomenon.

Future studies on this topic may also seek to examine how such attitudes may differ between rural and urban populations. Several researchers (see Jasper \& Nelkin 1992[25]; Ormandy \& Schuppli 2014) [35] have already established that rural and urban locales around the world 
provide distinctive opportunities for contact and relationships with animals and this may shape persons' attitudes toward them. Such a study promises to provide insightful data on Trinidad's population because animal uses differ within the twin island's countryside and city centers. That is, pastured farm animals reared for food are a common sight in the rural parts of Trinidad while the caged exotic animals of the Emperor Valley Zoo is the norm in urban areas such as the island's capital, Port-of-Spain.

Furthermore, given that this study found more positive attitudes among female students, this apparent gender bias in welfare attitudes should be addressed. It is suggested that Humane Education Programmes (HEPs) be targeted toward male student groups in an effort to improve student concerns about animal welfare. Female facilitators and animal behaviorists currently conduct the AWN Primary School Education Program thus, one possible suggestion is for this program to incorporate male facilitators in an attempt to appeal to male audiences given previous documentation of the influence of male role models and instructors upon boys' self-perceptions (Lippa 2002)[26] and learning (Dee 2006)[10]. However, the likelihood of men becoming more involved in humane education may be curtailed given the Caribbean's homophobic culture (Youseff 2010) [49] and Gaarder's (2011)[18] position that women have always fuelled movements of animal advocacy.

While a statistically significant relationship was not established between area of study and student attitudes toward animal welfare, the UWI School of Veterinary Medicine may consider incorporating courses on humane education and animal welfare into the program syllabus since no such course is currently offered. The finding by Hazel et al. (2011)[19] that veterinary student welfare scores increased after completing taught welfare courses justifies this recommendation. If this finding by Hazel et al. (2011)[19] holds true and welfare courses are introduced at the UWI, subsequent research into veterinary student attitudes at the Mt. Hope campus may reveal higher pro-welfare scores among this cohort.

This study also found that respondents were opposed to the archaic display of animals in cages and doubted that the Emperor Valley Zoo could sufficiently replace the natural environment of the giraffes by providing a suitable alternative. The significance of this finding is twofold. First, it is indicative of a growing preference for more naturalistic enclosures and consequently it hints toward increased concern for the welfare of captive animals. The end product of the on-going upgrade projects at the Emperor Valley Zoo should be reflective of growing public interest in more naturalistic environments for animal residents. These naturalistic displays may even serve an educational purpose, as they will allow zoo visitors to observe Mandela, Melman and the other animals in settings that mimic those of their natural habitats and learn about the environments within which these species thrive.
Second, this negative attitude toward displaying caged animals may be representative of a shifting ideology regarding the display and use of animals for human entertainment and challenges traditional notions of HAI. This finding therefore points toward a gradual movement away from the ideology of the natural human right to dominate nature as explained by Nibert.

\subsection{Humane Education and Animal Welfare Implications}

This apparent shifting ideology may indicate promise in global efforts to improve the welfare of captive, domestic and wild animals. For instance, student opposition to sport hunting and caged animal displays at the Emperor Valley Zoo suggest that students are educated about, or at least aware of the stress animals endure due to these practices. Thus, future studies on this zoo may seek to discover if its visitors consider their outing to be educational especially since the Animal Attitude Scale did not measure the educational component of zoos.

While the present study found that students were generally concerned about the welfare of animals and expressed positive attitudes toward welfare issues, efforts must be made to further educate students about such welfare concerns. The introduction of the AWN Primary School Education Programme may serve as evidence that attempts are being made to highlight the topic of animal welfare throughout Trinidad and Tobago. In this regard, it can be anticipated that the country's multi-ethnic multi-racial student population will continue to be sensitized to the welfare needs of animals.

\section{Conclusions}

This study has provided a glimpse into the animal welfare attitudes of a small number of Trinidadian tertiary students. Overall, this study reported that even though female students expressed more concern for both animal welfare and Mandela and Melman, pro-welfare attitudes were recorded for all students surveyed. Though this finding is hopeful, efforts must be made to maintain and even improve student concern about animal welfare since such attitudes affect how nonhuman animals are treated and this may have a ripple effect on reducing speciesism. Nevertheless, it is important to acknowledge the complexity of gender and the subsequent effects of this upon attitudes toward animal welfare in Trinidad.

This study also brought to light the changing notions about zoos and the shifting paradigms regarding their roles in captive animal display and conservation efforts. The attitudes discovered through this research represent a step in the right direction since students appeared to sensitive to the needs of captive animals. Nevertheless, much awareness is yet to be raised and considerable ground is 
still to be covered by Caribbean researchers, theorists and practitioners especially since studies on animal welfare studies are currently very limited.

The findings of this research both contradict and confirm Nibert's explanations of speciesism. Instances of contradiction- as is the case with student opposition to zoo cages and circus animal acts- serve as evidence that Nibert's ideas may need to be modified as his assumptions cannot be used to explain the complex attitudes toward HAI among Trinidadian youths. However, Nibert's ideas provided a suitable framework for informing the current study though future Caribbean research should incorporate theories that speak directly toward animal welfare.

The weak statistical relationship established between area of study and welfare attitudes flags this area as one that requires future scrutiny. This result - compounded by the previously identified methodological limitations highlights that further investigation of factors impacting the attitudes of Trinidadian veterinary students toward animal welfare is still needed. Though this research did not provide an overall evaluation of the existing veterinary program at the Mt. Hope campus, the results suggest that incorporating an element of taught courses on animal welfare into the syllabus should be considered especially since Arbour et al. (2009) [1] have documented the effectiveness of this instruction.

The recommendations that arose from this study must be considered within the parameters of the study's sample and population. Nevertheless, findings from this research may enhance existing knowledge about student attitudes toward the use and captive display of nonhuman animals in contemporary Trinidadian society especially due to the lack of such research in Trinidad and Tobago and throughout the wider Caribbean region.

\section{REFERENCES}

[1] Arbour, R., Signal, T., \& Taylor, N. (2009). Teaching Kindness: The Promise of Humane Education. Society and Animals 17: 136-148.

[2] Baker, P. (1981). Learning Sociology and Assessing Critical Thinking. Teaching Sociology 8(3), 325-363.

[3] Baron-Cohen, S. (2011). Zero degrees of empathy: A new theory of human cruelty and kindness. London: Penguin.

[4] Bekoff, M. \& Gruen. L. (1993). Animal Welfare and Individual Characteristics: A Conversation against Speciesism. Ethics and Behaviour 3(2), 163-175.

[5] Berk, L. E. (2006) Development of Sex Differences and Gender Roles. Child Development (7th ed.) Robert S. Feldman. Boston: Pearson.

[6] Bousfield, B., \& Brown, R. (2010) “Animal Welfare.” Veterinary Bulletin - Agriculture, Fisheries and Conservation Department Newsletter 1(4), 1-12.
[7] Broom, D. (n.d) “Animal welfare: future knowledge, attitudes and solutions.” Retrieved from http://www.australiananimalwelfare.com.au/app/webroot/fi les/upload/files/Animal\%20welfare\%20-\%20future\%20kn owledge,\%20attitudes\%20and\%20solutions.pdf

[8] Davey, G. (2006) Chinese University Students Attitudes toward the Ethical Treatment and Welfare of Animals. Journal of Applied Animal Welfare Science 9(4), 289-297. Web.

[9] de Boo, J., \& Knight, A. (2005) Concepts in Animal Welfare: a Syllabus in Animal Welfare Science and Ethics for Veterinary Schools. Journal of Veterinary and Medical Education 32(4): 451-453.

[10] Dee, T.S. (2006) The Why Chromosome. Education Next 6.4: 69-75.

[11] Dell'Amore, C. "Copenhagen Zoo Kills 4 Lions After Controversial Giraffe Death.” National Geographic, 15 Mar. 2014. Web. 20 Jan 2015. Retrieved from http://news.nationalgeographic.com/news/2014/03/140326 -lions-copenhagen-zoo-killing-animals-world-science/

[12] Fa, J.E., Gusset, M., Flesness, N., \& Conde, D.A. (2014) Zoos have yet to unveil their full conservation potential. Animal Conservation, (17), 97-100.

[13] Fernandez, E., Tambroski, M., Picken, S., \& Timberlake, W. (2009) Animal-visitor interactions in the modern zoo: conflicts and interventions. Applied Animal Behaviour Science 120, 1-8.

[14] Fielding, W. Knowledge of animal welfare and prevalence of dog care practices in New Providence, The Bahamas. (n.d). Retrieved fromhttp://www.hsi.org/assets/pdfs/2008_ caribbean_animal-welfare_conference/humane_education_ survey_bahamas.pdf

[15] Fielding, W. (2008) Establishing a Typology for Dogs in the English Speaking Caribbean. The College of the Bahamas Research Journal 14, 13-18. Web.

[16] Fielding, W. and Ostberg, A. (2008) Animal Welfare in the Wider Caribbean in 2008, with emphasis on dogs. Retrieved from http://www.fao.org/fileadmin/user_upload/animalwel fare/Animal\%20welfare\%20in\%20the\%20wider\%20Carib bean\%20in\%202008.pdf

[17] Fravel, L. (Nov. 2003) Critics Question Zoos’ commitment to Conservation. National Geographic. Web. Retrieved fromhttp://news.nationalgeographic.com/news/2003/11/11 13_031113_zoorole.html

[18] Gaarder, E. (2011) Women and the animal rights movement. Rutgers University Press, Print.

[19] Hazel, S., Signal, T.D., \& Taylor, N. (2011) Can Teaching Veterinary and Animal-Science Students about Animal Welfare Affect Their Attitude toward Animals and Human-Related Empathy? Journal of Veterinary Medical Education 38(1), 74-83. Web.

[20] Herzog, H. (2002) Darwinism and the Study of Human-Animal Interactions. Society and Animals 10.4: 361-367.

[21] Herzog, H. (2007) Gender Differences in Human-Animal Interactions: A Review.” Anthrozoos 20(1), 7-21. Web. 
[22] Herzog, H., Betchart, N., \& Pittman, R. (1991) Sex role orientation and attitudes toward animals. Anthrozoos 4(3), 184-192. Web.

[23] Hosey, G., \& Melfi, V. (2014) Human-Animal Interactions, Relationships and Bonds: A review and analysis of the Literature. International Journal of Comparative Psychology 27(1), 117-142.

[24] Irvine, L. (2008) Animals and Sociology. Sociology Compass 2(6), 1954-1971.

[25] Jasper, J. \& Nelkin, D. (1992) The Animal Rights Crusade. New York: The Free Press. Web. Kallipoliti, L. Evolution of the Zoo. Retrieved from http://gsappstudioxthessaloniki. files.wordpress.com/2011/07/history-of-zoos_lydia-kallipo liti.pdf

[26] Lippa, R. (2002) Gender, Nature, and Nurture. London: Lawrence Erlbaum Associates.

[27] Lusk, J., \& Norwood, F. (2012) Speciesism, altruism and the economics of animal welfare. European Review of Agricultural Economics 39, 189-212.

[28] Marino, L., Lilienfeld, S., Malamund, R., Nobis, N., \& Broglio, R. (2010) Do Zoos and Aquariums Promote Attitude Change in Visitors? A Critical Evaluation of the American Zoo and Aquarium Study. Society and Animals $18,126-138$.

[29] Marshall, A. (Jan. 2014.). Homophobia in the Caribbean. The New York Times. Retrieved from http://www.nytimes.com/roomfordebate/2014/01/29/why-i s-latin-america-so-progressive-on-gay-rights/homophobia-i n-the-caribbean

[30] Mathews, S., \& Herzog, H. (1997) Personality and attitudes towards the treatment of animals. Society and Animals 5(2), 57-63.

[31] Mazur, N., \& Clark, T. W. (2001) Zoos and conservation: Policy-making and organizational challenges. Bulletin Series Yale School of Forestry and Environmental Studies 105: 185-201.

[32] Moriarty, P. (1998) Zoos and Conservation Programs. Journal of Applied Animal Welfare Science 1(4), 377-380.

[33] Morris, B. (1998) The Power of Animals: An Ethnography. New York: Bloomsbury Academic.

[34] Nibert, D. (2003) Humans and Other Animals: Sociology's Moral and Intellectual Challenge. International Journal of Sociology and Social Policy 23(3), 5-25.

[35] Ormandy, E. \& Schuppli, C. (2014) Public Attitudes toward Animal Research: A Review. Animals 4, 391-408.

[36] Paul, E.S., \& Podberseck, A.L. (2000). Veterinary education and students' attitudes toward animal welfare. Veterinary Record 146: 269-272.

[37] Phillips. C.J.C., \& McCullough, S. (2005) Student attitudes on animal sentience and use of animals in society. Journal of Biological Education 40: 1-8.

[38] Pifer, L.K. (1996). Exploring the Gender Gap in Young Adults' Attitudes about Animal Research. Society and Animals 4(1), 37-52.
[39] Rhoads, D.L., \& Goldsworthy, R.J. (1979). The effects of zoo environments on public attitudes toward endangered wildlife. International Journal of Environmental Studies 13: 283-287.

[40] Rickles, M. L., Schneider, R. Z., Slusser, S. R., Williams, D. M., \& Zipp, J. F. (2013) Assessing change in student critical thinking for introduction to sociology classes. Teaching Sociology, 41.3: 271-281.

[41] Serpell, J. (1996) in the company of animals: A study of human-animal relationships. Cambridge: Cambridge University Press.

[42] Serpell, J.A. (2004). Factors influencing human attitudes to animals and their welfare. Spec. issue of Animal Welfare 13: 145-151.

[43] Shea, R. Are Wildlife Sanctuaries Good for Animals? (Mar. 2014). National Geographic. Retrieved from http://news.nationalgeographic.com/news/2014/03/140320 -animal-sanctuary-wildlife-exotic-tiger-zoo/

[44] Signal, T. D., \& Taylor, N. (2006b). Attitudes to animals within the animal protection community compared to a normative community sample. Society \& Animals 14.3: 265-274.

[45] Smith-Spark, L \& Brumfield, B. (June 2014). Zoo kills neglected bear cub, will stuff it for children to learn 'nature can be cruel.' CNN. Retrieved from http://edition.cnn.com/2014/06/26/world/europe/switzerlan d-bear-cub-stuffed/

[46] Steinbock, B. (1978) Speciesism and the Idea of Equality. Philosophy 53: 247-256.

[47] Tyson, L. (Mar. 2015). No half-measures: While there are zoos, the killings will continue.” CNN. Retrieved from http://edition.cnn.com/2014/03/27/opinion/lion-cull-anti-z oo-argument/

[48] Vaughan, A. Man pours beer over tiger as London zoo Lates parties get out of hand. (Jul. 2014). Retrieved from http://www.theguardian.com/environment/2014/jul/18/lon don-zoo-party-night-animal-welfare

[49] Youseff, V. (2010) "The Culture of Violence in Trinidad and Tobago: A Case Study.” Caribbean Review of Gender Studies 4: 2-9. Web. 